\title{
Ecological landscape elements: long-term monitoring in Great Britain, the Countryside Survey 1978-2007 and beyond
}

\author{
Claire M. Wood ${ }^{1}$, Robert G. H. Bunce ${ }^{2}$, Lisa R. Norton ${ }^{1}$, Lindsay C. Maskell ${ }^{1}$, Simon M. Smart ${ }^{1}$, \\ W. Andrew Scott ${ }^{1}$, Peter A. Henrys ${ }^{1}$, David C. Howard ${ }^{1}$, Simon M. Wright ${ }^{1}$, Michael J. Brown ${ }^{1}$, \\ Rod J. Scott ${ }^{1}$, Rick C. Stuart ${ }^{1}$, and John W. Watkins ${ }^{1}$ \\ ${ }^{1}$ Centre for Ecology \& Hydrology, Lancaster Environment Centre, Bailrigg, Lancaster, LA1 4AP, UK \\ ${ }^{2}$ Estonian University of Life Sciences, Kreuzwaldi 5, 51014 Tartu, Estonia
}

Correspondence: Claire M. Wood (clamw@ceh.ac.uk)

Received: 25 October 2017 - Discussion started: 8 November 2017

Revised: 22 March 2018 - Accepted: 22 March 2018 - Published: 16 April 2018

\begin{abstract}
The Countryside Survey (CS) of Great Britain (GB) provides a unique and statistically robust series of datasets, consisting of an extensive set of repeated ecological measurements at a national scale, covering a time span of 29 years. CS was first undertaken in 1978 to provide a baseline for ecological and land use change monitoring in the rural environment of GB, following a stratified random design, based on $1 \mathrm{~km}$ squares. Originally, eight random $1 \mathrm{~km}$ squares were drawn from each of 32 environmental classes, thus comprising 256 sample squares in the 1978 survey. The number of these sites increased to 382 in 1984, 506 in 1990, 569 in 1998 and 591 in 2007. Detailed information regarding vegetation types and land use was mapped in all five surveys, allowing reporting by defined standard habitat classifications. Additionally, point and linear landscape features (such as trees and hedgerows) are available from all surveys after 1978. From these stratified, randomly located sample squares, information can be converted into national estimates, with associated error terms.

Other data, relating to soils, freshwater and vegetation, were also sampled on analogous dates. However, the present paper describes only the surveys of landscape features and habitats. The resulting datasets provide a unique, comprehensive, quantitative ecological coverage of extent and change in these features in GB. Basic results are presented and their implications discussed. However, much opportunity for further analyses remains.

Data from each of the survey years are available via the following DOIs: Landscape area data 1978: https://doi.org/10.5285/86c017ba-dc62-46f0-ad13-c862bf31740e, 1984: https://doi.org/10.5285/b656bb43448d-4b2c-aade-7993aa243ea3, 1990: https://doi.org/10.5285/94f664e5-10f2-4655-bfe6-44d745f5dca7, 1998: https://doi.org/10.5285/1e050028-5c55-42f4-a0ea-c895d827b824, and 2007: https://doi.org/10.5285/bf189c5761eb-4339-a7b3-d2e81fdde28d; Landscape linear feature data 1984: https://doi.org/10.5285/a3f5665c-94b24c46-909e-a98be97857e5, 1990: https://doi.org/10.5285/311daad4-bc8c-485a-bc8a-e0d054889219, 1998: https://doi.org/10.5285/8aaf6f8c-c245-46bb-8a2a-f0db012b2643 and 2007: https://doi.org/10.5285/e1d312454c0a-4dee-b36c-b23f1a697f88, Landscape point feature data 1984: https://doi.org/10.5285/124b872e-036e4dd3-8316-476b5f42c16e, 1990: https://doi.org/10.5285/1481bc63-80d7-4d18-bcba-8804aa0a9e1b, 1998: https://doi.org/10.5285/ed10944f-40c8-4913-b3f5-13c8e844e153 and 2007: https://doi.org/10.5285/55dc5fd7d3f7-4440-b8a7-7187f8b0550b.
\end{abstract}




\section{Introduction}

The Countryside Survey (CS) of Great Britain (GB) was initiated in the late 1970s for the surveillance and monitoring of ecological and land cover change in the rural environment using quantitative and repeatable methods. Retaining standardised methods to describe the habitats, landscape features, land use, soils, freshwater and vegetation present, has allowed data for subsequent surveys to estimate change. The survey provides a wealth of ecological data, consisting of a detailed range of measurements at a national scale, covering five surveys across a time span of 29 years (1978-2007), with the intention of future repeat surveys. The history of the development of the methodology is given by Sheail and Bunce (2003). A number of simultaneous surveys have also been undertaken in Northern Ireland (Cooper et al., 2009), complementing the GB survey, and enabling reporting for the United Kingdom (UK) as whole. However, the data from GB are the focus of this paper.

The survey is based on $1 \mathrm{~km}$ squares as a conveniently sized unit for landscape monitoring. This had previously been tested in Cumbria (1975) (Bunce and Smith, 1978) and Shetland (1974) (Wood and Bunce, 2016) in the years preceding the first GB survey in 1978. The survey design is based on a series of distributed, stratified, randomly selected $1 \mathrm{~km}$ sample squares from across Britain, which numbered 256 in 1978, 382 in 1984, 506 in 1990, 569 in 1998 and 591 in 2007 (Fig. 1). The stratification used is the ITE Land Classification of $1 \mathrm{~km}$ squares in GB (Fig. 2), which is based on a statistical analysis of topographic, physiographic and climatic attributes as described in (Bunce et al., 1996a, c) and summarised in Sect. 2.

The most geographically comprehensive element of the survey is the mapping of land cover and ecologically relevant landscape features, carried out in every survey undertaken thus far (1978, 1984, 1990, 1998, and most recently, 2007). Across survey areas of $1 \mathrm{~km}$ square, area, line and point features are mapped onto base maps, using a range of pre-determined coded options. Areas are categorised by predominant vegetation characteristics and, in 2007, were assigned to broad and priority habitats (Jackson, 2000; Maddock, 2008), which are able to be translated into the habitats of Annex 1 of the EU Habitats directive (Romão, 2013). Mapping was initially carried out using waterproof paper base maps, but for the first time in 2007, data were collected in digital format using rugged field computers.

With the inclusion of the vegetation data (as described in Wood et al., 2017), soils and freshwater data (Emmett et al., 2010; Dunbar et al., 2010; Williams et al., 2010; Carey et al., 2008), the survey as a whole provides a wide range of nationally significant ecological datasets, globally unique in their geographical coverage and time span. The co-registration of all the data, in both time and space, along with the flexibility in coding make the datasets unique in describing and interpreting the drivers of change in the British landscape. In par- ticular, other examples of field-mapped land cover data sets, with their potential for assessing detailed changes in countryside structure at a national level, are not known to the authors. The majority of other field habitat mapping projects are one-off exercises which are not intended to monitor change and do not use repeatable methods. Monitoring requires more stringent procedures to ensure that differences recorded represent real change and not distortions due to differences between observers or recording technique, as described by Brandt et al. (2002). One commonly used option for landscape mapping is the use of large-scale land cover maps, largely derived from satellite or aerial imagery (Cole et al., 2015; Mayaux et al., 2004; Eva et al., 2004; Bartholomé and Belward, 2005). None of these examples include the same level of detail, with the same potential for assessing change or integrating with co-located in situ data, over such a time span as the data from the Countryside Survey. Whilst the CS field data are complemented by a series of land cover maps (Morton et al., 2011; Fuller et al., 1994a, 2001), which are useful for determining habitat extent, they do not provide data to determine habitat quality and condition, habitat change or the extent and condition of landscape point and line features.

\section{Survey design: site selection and stratification}

Following preliminary work undertaken within smaller regions of Britain (Wood and Bunce, 2016; Bunce and Smith, 1978), a sample unit of $1 \mathrm{~km}$ square was found to be an effective size for capturing data within CS. A $1 \mathrm{~km}$ square is small enough to survey in a relatively short period of time (1 week or less) and yet large enough to contain sufficient environmental features to allow differentiation of the character of squares, and interaction between components to be examined.

With over 240000 one-kilometre squares in GB, a sampling approach was essential and a statistical environmental classification was constructed from which stratified, random samples were taken. This classification covered the whole of Great Britain using multivariate analysis of environmental factors, for example altitude and climate (converted into attributes which the statistical methods at the time could analyse) from each $1 \mathrm{~km}$ square (Bunce et al., 1996b). A primary objective of this methodology was to minimise bias, as the classification divides the population into discrete strata that are then used to derive samples from which ecological parameters such as vegetation can be recorded. By using this statistically robust method, it is then possible to scale up the results from the sample sites to describe the entire population, with associated error terms.

The sampling methodology was initially developed at regional scales in the early 1970s, for example in Shetland and Cumbria (Bunce and Smith, 1978; Wood and Bunce, 2016). Later it was extended to the whole of GB, but only 


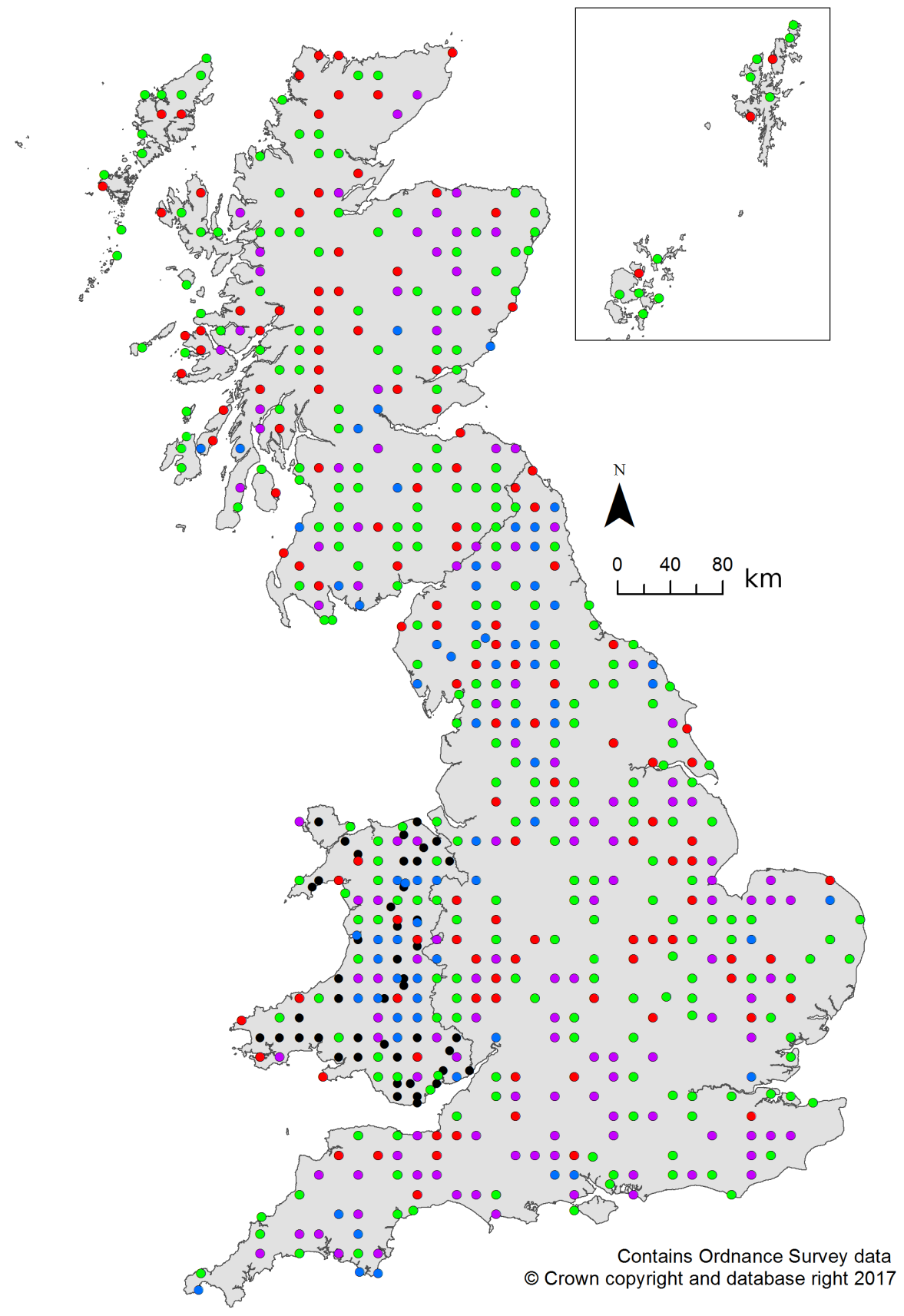

Year sample square first surveyed

$$
\text { - } 1978 \text { • } 1984 \text { • } 1990 \text { • } 1998 \text { • } 2007
$$

Figure 1. Map of sampling locations across Britain.

on a grid of $1225 \times 1 \mathrm{~km}$ squares as a consequence of the limitations of computing power at the time. By the end of the 1980s, all $1 \mathrm{~km}$ squares in GB had been classified into the same 32 strata, which was not technically possible at the start of the 1970s. Known as the "Institute of Terrestrial Ecology (ITE) Land Classification of Great Britain" (Bunce et al., 1990, 1996a, b), it has evolved over the 30-year period (Sheail and Bunce, 2003) latterly to allow the reporting of separate national estimates for Scotland (1998), and then Wales (2007). However, changes in the stratification have all been conservative so as not to compromise previous work, and the basic stratification still underpins CS, now with 


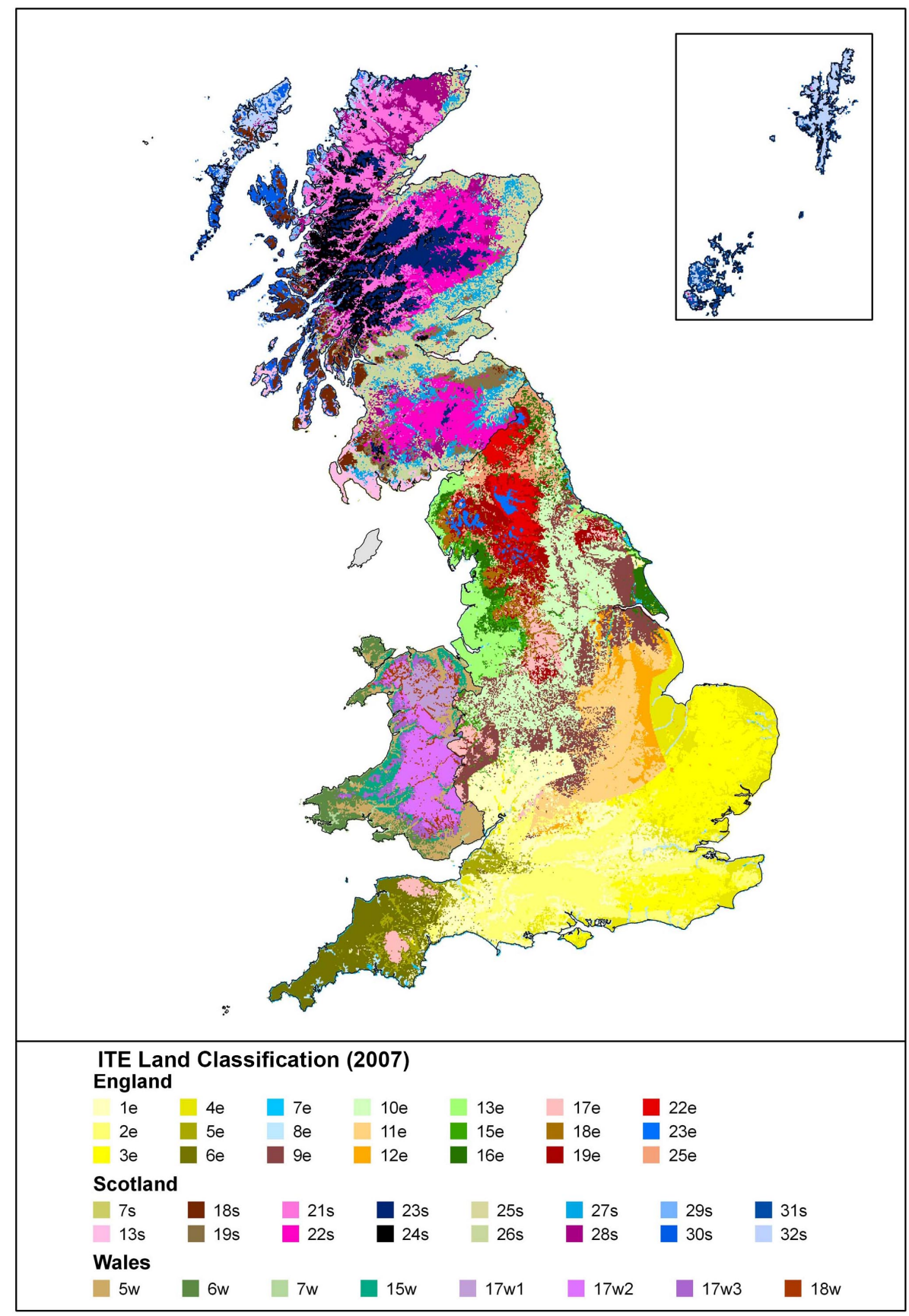

Figure 2. ITE Land Classification, 2007. (Contains Ordnance Survey data (@) Crown copyright and database right 2018.)

45 strata (or "land classes"). Further details are provided in Wood et al. (2017) and Barr and Wood (2011). This successful method of the consistent classification of land into relatively homogenous strata has been proven to provide a valuable spatial framework as the basis for monitoring ecological indicators across large areas. There are now several examples of where the British methods have been emulated effectively, including Northern Ireland (Cooper, 2000), Spain (Elena-Rosselló, 1997), Norway (Bakkestuen et al., 2008),
Sweden (Ståhl et al., 2011), Estonia (Villoslada et al., 2016) and Europe (and the whole world) (Metzger et al., 2013).

\subsection{Sampling sites}

Having generated the classification to act as the sampling stratification system, the number of samples to be surveyed in the first (1978) survey was considered. Ideally, this number would depend on the size of the stratum (i.e. how many $1 \mathrm{~km}$ 


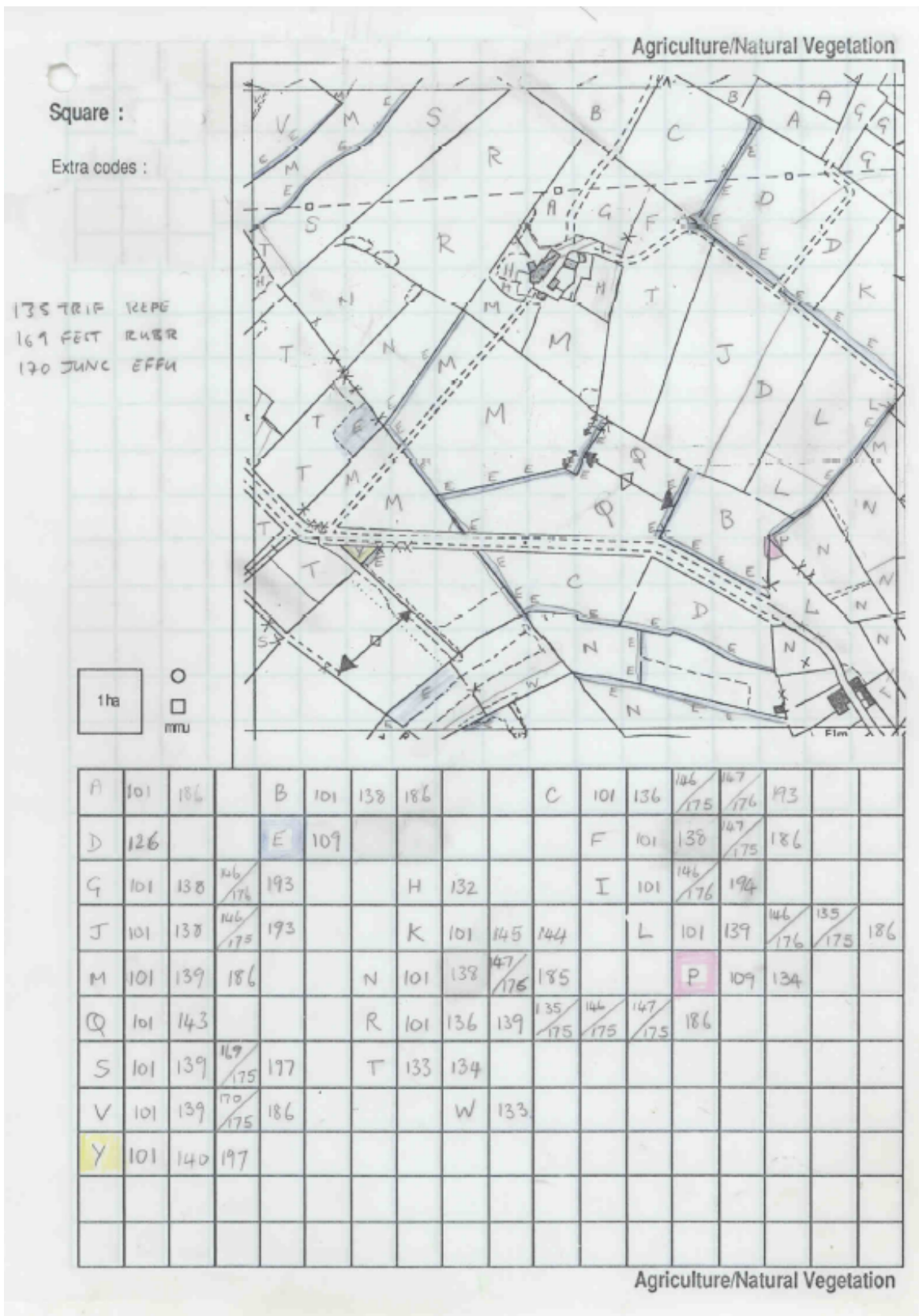

Figure 3. Example of a field mapping sheet.

squares of the land class occurred in GB) and on the ecological variability within the stratum. Preliminary work had suggested that, for ecological surveys of this type, at least eight samples per stratum were necessary in order to be representative of that stratum. As resources were constrained, eight squares were thus selected at random from each of the strata/land classes. These squares were taken from the grid of classified squares and thus the final sample for the first GB survey was a gridded, stratified, random sample of 256 onekilometre squares. The survey was carried out in the summers of 1977 (when a few pilot squares were sampled) and
1978 and focused on vegetation quadrats and soils; habitat areas were also mapped. In subsequent surveys, the number of $1 \mathrm{~km}$ squares sampled increased with each survey to a total of 591 in 2007. By 2007, the number of squares sampled from within each land class varied with the size of the stratum. The majority of squares have been repeated in each survey. However, occasionally a square may have been refused access by the landowner, in which case a replacement square would be chosen at random to replace the refused square, from within the same land class. The key requirement is that enough squares are surveyed from within each land class in 


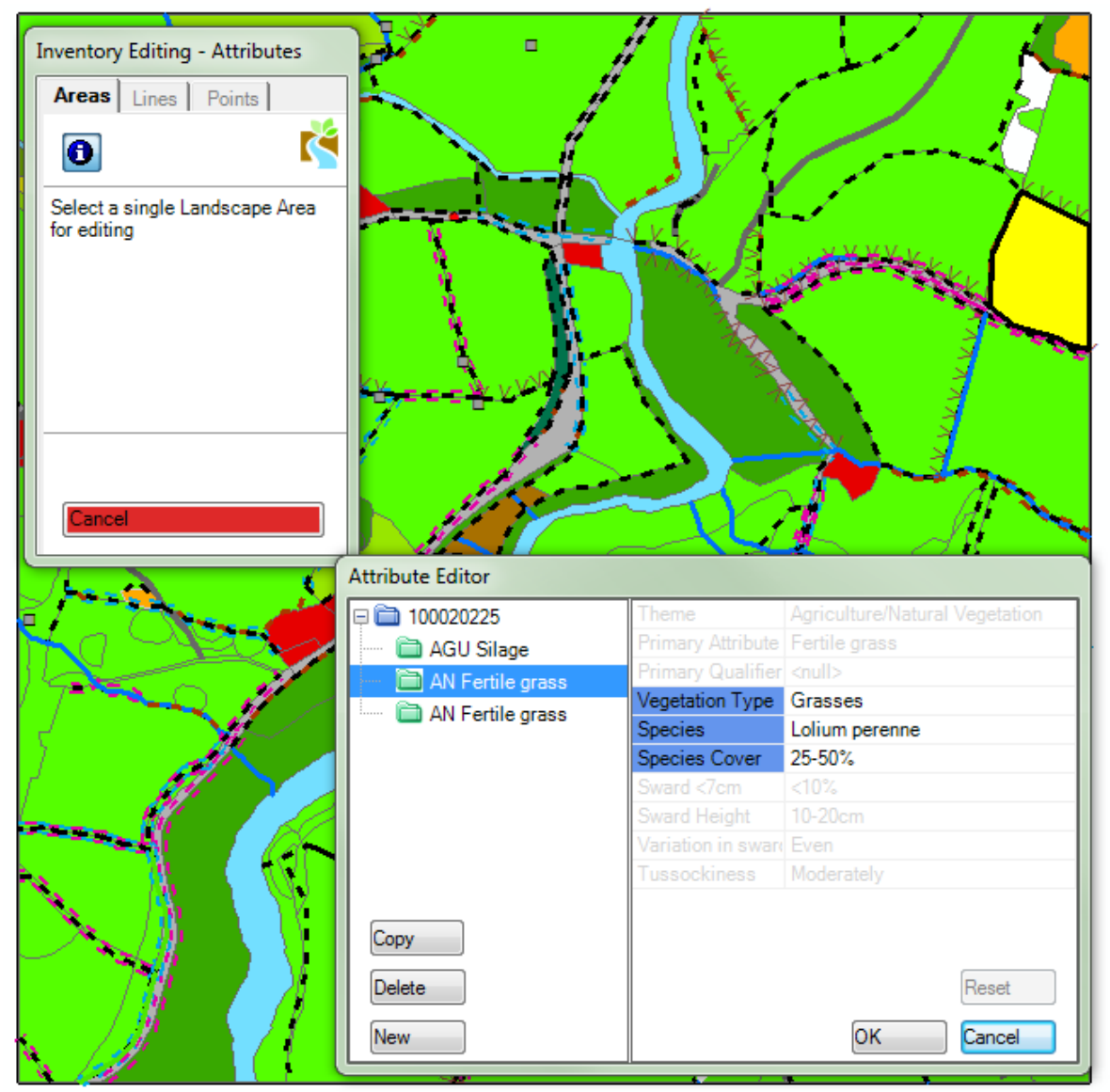

Figure 4. Example of digital mapping interface.

order to provide statistically valid estimates of features for each land class area. These issues are described in detail in Barr and Wood (2011).

\subsection{Data collection methods}

The mapping component of CS was carried out in the 1978, 1984, 1990, 1998 and 2007 surveys. When the methods for CS were first tested in the 1970s, the earlier regional surveys relied on vegetation plots to sample the habitats, features and vegetation types in question, together with a record of description codes, as described in Wood and Bunce (2016). By 1978 , it was realised that plot sampling points alone were failing to capture the range of land cover variation within squares, and mapping the land cover across the square would address this issue. Whilst the five distributed randomly located vegetation plots (per $1 \mathrm{~km}$ square), with additional plots to represent rivers, roads and hedges are a key aspect of the survey for measuring habitat quality, field mapping was introduced to the survey to obtain more robust estimates of habitat extent. Predetermined standard codes, described below, were used to define land cover categories which could be converted into habitat classes. Within each survey area of
$1 \mathrm{~km}$ square, areal, line and point features are mapped onto base maps, using a range of pre-determined coded options, using the methodologies outlined below. For the 1978, 1984, 1990 and 1998 surveys, features were mapped onto a range of paper base maps (see Fig. 3 for an example from 1990), arranged into "themes" (for example, "agriculture and natural vegetation", "forestry", "structures"). In 2007, surveyors used electronic data capture equipment for the first time in CS, and new electronic mapping software ("CS Surveyor") was developed by the Centre for Ecology \& Hydrology, in conjunction with the GIS software company Esri UK. This enabled all features to be mapped onto the same, digital, base map (Fig. 4), allowed more rapid reporting of results and allowed for validation in the field.

\section{Mapped features}

\subsection{Area features}

In the first survey in 1978, areas of distinct land cover types were drawn on base maps, then later transferred onto Ordnance Survey (the UK's national mapping agency) 1 : 10000 base maps using a set of 80 codes (see Wood et al., 
2012). Cover types were mainly differentiated using dominant plant species, reflecting traditionally taught divisions between habitats based on indicator species. In the 1984 survey, the $1: 10000$ base maps were annotated with an updated set of codes, but maintaining the integrity of the previous definitions. Parcels and features were labelled on the map with alphabetic codes, and a set of numeric feature codes were recorded against each alphabetic map code. The surveyors entered information about each mapped polygon, including land use (crop, grazing animals etc.) and at least the two most common species. The full code list is given in Barr (1984). The approach in 1990 was similar to 1984, again with a slightly updated codes list (Barr, 1990). Updating of codes reflected experience of habitat combinations gained in the field from previous surveys.

Methods of classifying land cover types in GB evolved (for example, see Wyatt et al., 1994) and immediately prior to the 1998 CS, the broad habitat system was devised and introduced by the Joint Nature Conservation Committee (Jackson, 2000). As the surveys in 1978, 1984 and in 1990 were carried out using earlier definitions for habitats that were not directly related to the broad habitat classification, a translation protocol had to be developed to ensure that past data would remain valuable for investigating change. The 1978 data were translated to broad habitats in 2009 (Wood et al., 2012). In a few cases, the translation of the 1978, 1984 and 1990 into the broad habitats has not been straightforward, due to inherent overlap between habitat classes. It had been possible, however, due to the nature of the codes recorded in the field which are recorded in a disaggregated manner, allowing the translation of parcels into different reporting categories, such as the broad habitats, or for example European Annex 1 categories (Bunce et al., 2013). In the case of the broad habitat categories, translation errors have been minimised by checks for consistency across surveys.

Broad and priority habitats were identified in the field using a key developed in 1998 (for the 1998 survey) and updated with improvements between 2001 and 2006 in time for the 2007 survey (see Maskell et al., 2008) utilising advice from many experts on UK Biodiversity Action Plan (BAP) definitions. The habitat key provides detailed guidance on how to assign areas to habitat classes using indicator species as well as physiography and dominant plant cover. It includes a key to the newly classified priority habitats (Maddock, 2008) which were incorporated in the 2007 survey; polygons assigned to a priority habitat in 2007 could be "back-allocated" to 1998 if the surveyor judged the patch had not changed across that time period. As well as mapping priority habitats, observers recorded associated species and were also encouraged to place a $2 \mathrm{~m} \times 2 \mathrm{~m}$ targeted sampling plot in each priority habitat if it did not already have an existing plot located in it (Wood et al., 2017). For the earlier surveys, priority habitats were assigned where there was an existing habitat code that matched the current definition (for example, "Coastal Saltmarsh").
All features were mapped using a minimum mappable unit (MMU) of $400 \mathrm{~m}^{2}(20 \mathrm{~m} \times 20 \mathrm{~m}$ through to $80 \mathrm{~m} \times 5 \mathrm{~m})$. No habitat was mapped as a separate unit unless it had at least this extent. If surveyors felt that an important feature was not being captured they could either create mosaics of different habitats or map elements as points or lines; clear instructions were set out the field handbooks.

In the 1998 and 2007 surveys, surveyors concentrated particularly on identifying and mapping where change had taken place between surveys, with surveyors referring to the previously mapped data when surveying (with the exception of squares being mapped for the first time).

\subsection{Linear features}

Linear features are landscape elements less than $5 \mathrm{~m}$ wide that form lines in the landscape. CS records the length and condition of a range of linear features predominantly, but not exclusively, describing boundaries. These include managed woody linear features (i.e. hedges), unmanaged woody linear features (i.e. lines of trees), walls, fences, streams and a range of other linear features. Recorded linear features have a minimum length of $20 \mathrm{~m}$ and may include gaps of up to $20 \mathrm{~m}$. All linear features are recorded unless they form part of a curtilage or they are within the woodland canopy. Woody linear features, including hedges, remnant hedges and lines of trees were classified using a key developed for CS in 20052006 (Maskell et al., 2008) following consultation with the Hedgerow Steering Group of the UK BAP. Precise definitions of features were recorded in the field handbooks (Barr, 1990, 1998; Maskell et al., 2008). Linear features were not recorded in detail in 1978 but were recorded subsequently in 1984, 1990, 1998 and 2007.

\subsection{Point features}

Point features are individual landscape elements that occupy less than an area of $20 \mathrm{~km} \times 20 \mathrm{~m}$. Point features may be trees or groups of trees, ponds and other freshwater features, physiological features such as cliffs, buildings and other structures with various use codes (for example, "residential" or "agricultural"). As with lines and areas, points are drawn and recorded on base maps using standard codes (Maskell et al., 2008).

\section{Data collected}

\subsection{Area data}

A summary of the categories of area data collected is given in Table 1. The areas of polygons allocated to broad habitats are available for each survey year. Additional information was collected in 1984, 1990, 1998 and 2007. This additional information includes the broad land use category of each polygon, a list of key species in the polygon and cover, 
Table 1. Data collected within mapped polygons.

\begin{tabular}{|c|c|c|c|c|c|c|}
\hline Attribute & Description & 1978 & 1984 & 1990 & 1998 & 2007 \\
\hline Broad/priority habitat area & BAP broad habitat & $x$ & $x$ & $x$ & $x$ & $x$ \\
\hline Theme & Broad land use category, e.g. "agricultural crops" & $(\times)$ & $x$ & $x$ & $\times$ & $x$ \\
\hline Primary attribute & Feature name, e.g. "potatoes" & $(\times)$ & $x$ & $x$ & $x$ & $x$ \\
\hline Species & Species where relevant & $(\times)$ & $x$ & $x$ & $x$ & $x$ \\
\hline Species cover & Cover of above species across polygon & & $x$ & $x$ & $x$ & $x$ \\
\hline Primary qualifier & Additional information pertaining to primary attribute & & $x$ & $x$ & $x$ & $x$ \\
\hline Structure use & Use, where theme is "structures" & & $x$ & $x$ & $\times$ & $x$ \\
\hline Physiography cover & Cover, used where theme is "inland physiography" & & $x$ & $x$ & $\times$ & $x$ \\
\hline Road verge A & Width of verge A where theme is "transport" & & $x$ & $x$ & $x$ & $x$ \\
\hline Road verge B & Width of verge B where theme is "transport" & & $x$ & $x$ & $\times$ & $x$ \\
\hline Modal DBH & $\begin{array}{l}\text { Modal diameter at breast height }(\mathrm{DBH}) \text {, where theme } \\
\text { is "forestry" }\end{array}$ & & $\times$ & $\times$ & $\times$ & $x$ \\
\hline Mosaic percent area & $\begin{array}{l}\text { If broad habitat is classed as mosaic, } \% \text { cover of } \\
\text { each primary attribute }\end{array}$ & & & & $x$ & $x$ \\
\hline
\end{tabular}

diameter at breast height $(\mathrm{DBH})$ of trees where the polygon is forestry, and the width of verges where the element is a "transport" type (such as a road).

\subsection{Linear feature data}

A summary of the categories of linear feature data collected is given in Table 2. Descriptions of features and attributes are available for each survey year between 1984 and 2007, with additional detail being collected in 1998 and 2007 regarding the condition of hedgerows, such as widths, signs of management, and margins.

\subsection{Point feature data}

A summary of the categories of point feature data collected is given in Table 3. Data on the type of feature have been collected in each survey since 1984, including details on species, use (where appropriate) and DBH of trees. Additional information regarding veteran trees was recorded in 1998 and 2007, when up to 10 veteran trees were recorded per square, consisting of the first two veteran trees of each species encountered in the field.

\section{Data quality}

Each field survey was carried out by teams of experienced botanical surveyors, and was preceded by an intensive training course, ensuring high standards and consistency of methodology, identification, effort and recording across CS according to criteria laid out in the field handbooks (Barr, 1984, 1990, 1998; Bunce, 1978; Maskell et al., 2008). During the surveys, survey teams were initially supervised and later monitored by experienced project staff.

Data were recorded on waterproof paper sheets in 1978, 1984, 1990 and 1998 and were subsequently digitised from the field sheets, following defined procedures. The digitised data have always been stored in secure, regularly backed-up databases. The 1984, 1990 and 1998 data were digitised in the 1990s, the linework being stored in Esri's ArcINFO ${ }^{\mathrm{TM}}$ geographical information system (Esri, 2017) coverages with the attributes being stored in an Oracle (Oracle Corporation, 2017) database. Before the 2007 survey, a data migration process was undertaken to transform each survey's data set into matching schemas, incorporating the point and linework and attributes into a geodatabase stored in Oracle and accessed via ArcSDE (Esri, 2017). The habitat polygons from 1978 were not digitised until 2009 (Wood et al., 2012), and were thus not reported in the main report for CS 2007 (Carey et al., 2008).

The move to electronic capture methods using a specially designed software package ("CS Surveyor") in 2007 removed the need for post-survey digitising and therefore eliminated a potential source of error. Improvements to data quality resulted from the inclusion of mandatory data entry fields for each feature, prompts for expected data for each of the mapped feature types and the removal of issues of illegible records. The use of a digital system enabled surveyors to ensure that each of the mapped components had been visited and to record whether change had occurred against each entry. This requirement to record change was a compulsory element of the survey, enforced by the digital system when any changes were made to mapped habitats and features. Additionally, the data were transferred back to the office soon after completion, enabling prompt data checking. Surveyors and managers could communicate readily to discuss any issues arising.

Surveyors had the ability to improve the quality of data from a prior survey by "back-allocating" features if they thought they had been recorded incorrectly in the previous survey. For example, if they encountered a large oak tree that had not been previously recorded, they would know that such 
Table 2. Data collected regarding linear features.

\begin{tabular}{|c|c|c|c|c|c|}
\hline Attribute & Description & 1984 & 1990 & 1998 & 2007 \\
\hline Length & Length of feature & $\times$ & $\times$ & $\times$ & $\times$ \\
\hline Theme & Feature name, e.g. "bank", "inland water", "woody linear feature" & $x$ & $\times$ & $x$ & $\times$ \\
\hline Primary attribute & Feature type, e.g. "stone bank", "canal" & $\times$ & $\times$ & $\times$ & $\times$ \\
\hline Height & Height of feature, where appropriate & $x$ & $\times$ & $x$ & $x$ \\
\hline Base height & Basal height of feature (hedgerow) & & & $x$ & $\times$ \\
\hline Width & Width of feature (hedgerow) & & & $\times$ & $\times$ \\
\hline Modal DBH & Diameter at breast height $(\mathrm{DBH})$, where appropriate & $\times$ & $\times$ & $x$ & $\times$ \\
\hline Condition & Condition assessment (walls, fences) & $\times$ & $\times$ & $x$ & $\times$ \\
\hline Historic management & Evidence of historic management (hedgerow) & & & $\times$ & $\times$ \\
\hline Evidence management & $\begin{array}{l}\text { Evidence of recent management (none, newly planted, cutting e.g. flail } \\
\text { or saw ( }<3 \text { years), laying or coppicing) ( }<5 \text { years), both of the preced- } \\
\text { ing two }\end{array}$ & & $x$ & $x$ & $x$ \\
\hline Staked trees & Staked individual trees within the feature (hedgerow) & & $\times$ & $\times$ & $\times$ \\
\hline Tree protectors & Tree protectors & & $\times$ & $x$ & $x$ \\
\hline Line of stumps & Whether feature is a line of stumps (hedgerow) & & $\times$ & $x$ & $x$ \\
\hline Vertical gappiness & $\%$ of breaks which extend from canopy to ground along hedgerow & & & $\times$ & $x$ \\
\hline Margin width left & Margin width on left side of feature & & & $\times$ & $\times$ \\
\hline Margin width right & Margin width on right side of feature & & & $x$ & $\times$ \\
\hline Species composition & Mixed species, $>50 \%$ hawthorn, $>50 \%$ other (hedgerow) & $\times$ & $\times$ & $\times$ & $\times$ \\
\hline Species & Tree/shrub species (hedgerow) & $\times$ & $\times$ & $\times$ & $\times$ \\
\hline Proportion & Proportion of species in feature (hedgerow) & $x$ & $\times$ & $\times$ & $x$ \\
\hline
\end{tabular}

Table 3. Data collected regarding point features.

\begin{tabular}{|c|c|c|c|c|c|c|}
\hline & Attribute & Description & 1984 & 1990 & 1998 & 2007 \\
\hline & Theme & Broad land use category e.g. "forestry", "building" & $\times$ & $x$ & $x$ & $\times$ \\
\hline & Primary attribute & Feature type, e.g. "individual tree" & $\times$ & $\times$ & $x$ & $x$ \\
\hline & Species & Species, where relevant & $\times$ & $x$ & $x$ & $x$ \\
\hline & Proportion & Proportion of species in feature & $\times$ & $\times$ & $x$ & $x$ \\
\hline & Use & Use where appropriate, e.g. "agricultural" & $x$ & $x$ & $x$ & $x$ \\
\hline & Buffer & Buffer zone present & & & $x$ & $\times$ \\
\hline & Modal DBH & Modal diameter at breast height (DBH) & $x$ & $x$ & $\times$ & $x$ \\
\hline \multirow[t]{10}{*}{ Veteran trees } & Tree dead & Dead tree & & & $\times$ & $\times$ \\
\hline & Missing limbs & Missing branches & & & $\times$ & $\times$ \\
\hline & Dead wood & Dead wood attached to trunk & & & $\times$ & $\times$ \\
\hline & Dead missing bark & Dead, loose missing bark & & & $\times$ & $\times$ \\
\hline & Lightning strikes & Evidence of lightning strikes & & & $\times$ & $\times$ \\
\hline & Hollow trunk & Hollow trunk or major rot sites & & & $\times$ & $\times$ \\
\hline & Veteran tree type & Standard, pollard or layered & & & $x$ & $\times$ \\
\hline & Epiphyte cover & Epiphytes: rare, present, abundant? & & & $\times$ & $\times$ \\
\hline & Ivy cover & Ivy cover: 30 or $>30 \%$ & & & $\times$ & $\times$ \\
\hline & Canopy live & $\%$ of canopy live & & & $x$ & $\times$ \\
\hline
\end{tabular}

a feature could not have grown in the few intervening years between surveys, and hence could confidently record that the feature must have been in existence in the previous survey, but must have missed being recorded. In this case, the information for the feature (point, line or area) would be backallocated in the database for the previous survey.

Quality assurance (QA) exercises were undertaken during the 1990, 1998 and 2007 surveys, which involved a second team of surveyors (QA assessors) repeating the survey for all or part of a square. The 1990 QA report (Prosser and Wallace, 1992) cited an $89 \%$ agreement between the field surveyors and QA assessors recording of primary land cover codes, and an $80 \%$ agreement for primary boundary codes. The 1998 report (Prosser and Wallace, 1999) gave an $88 \%$ agreement between the field surveyors and QA assessors recording of primary land cover codes, and an $85 \%$ agree- 
ment for primary boundary codes. In 2007 (Norton et al., 2008), an assessment was made of point features, which had an $89 \%$ agreement, and linear features, which had a $99 \%$ match and a $73 \%$ agreement at the polygon level. This last figure appears lower than the figures in the 1990 and 1998 assessments, but was assessed slightly differently, being at the broad/priority habitat level, rather than the primary code level. This introduced minor discrepancies (particularly between the choice of broad or priority habitat) which could largely be rectified with post-processing of the data.

A limitation of the datasets is that the exact site locations are held confidentially to protect landowner privacy (most sites are privately owned and surveys are only undertaken with prior permission), and also to secure the long-term nature of the project. As a consequence of this, the raw habitat data are not available as spatial datasets but rather as flat files, which may be analysed spatially at the level of the 45 environmental land classes, in conjunction with the ITE Land Classification dataset (Bunce et al., 2007). Regional estimates below the level of these land classes are not statistically robust due to sampling limitations, as described by Bunce et al. (1996b). National estimates are available in spatial formats, as detailed in Sect. 10. Within these national estimate datasets, statistical upper and lower limits are provided for each feature in question.

\section{Methodological development}

The success of the sampling methodology overall has been discussed in Wood and Bunce (2016). The method of habitat mapping is deemed to be highly successful for collecting the necessary data, and it is currently the only method that provides such detailed information at a national level, with the additional benefit of being able to assess change reliably. Where sufficient resource is available, changes to the methodology would not be recommended. However, although CS is a sample survey, field data collection is still a relatively expensive method of gathering information and various other options for capturing the same information have been proposed, particularly using remotely sensed methods. An assessment of using aerial photography to map habitats (in particular, condition) has been made in Wood et al. (2015). Broad habitats can be generally mapped from aerial photography, with some habitats, such as broadleaved woodland, being more successfully mapped from the air than others, such as fen, marsh and swamp. However, many elements, especially structural and species attributes, cannot be mapped successfully from the air. No detailed measurements or condition assessments were possible for any landscape feature from the aerial photos alone. Virtually no species were identified for most of the feature types (although infrared photography has now been used to improve habitat identification and composition; Ståhl et al., 2011). Several broad habitats rely on a thorough knowledge of the plant species occurring there, before a correct identification can be made. This is particularly important in differentiating between certain habitats, such as types of grassland and for the identification of priority habitats in particular (for example Purple Moor Grass Rush Pasture). In a survey such as CS, from which estimates for the whole of Great Britain are produced (Carey et al., 2008), a significant national underestimate of many features would result from mapping undertaken from aerial photos, and changes would be difficult, if not impossible, to assess. Similarly, although imagery available from drones is becoming more widespread, the detail remains below the level gained from field survey and whilst it could potentially be used to increase the speed and accuracy of mapping habitats and land cover extents, this would be at a cost.

These issues are also to be taken into account when assessing the use of satellite derived data, such as the series of land cover maps of Great Britain (Morton et al., 2011). Whilst these products give an excellent coverage of broad habitat extents for the whole of the United Kingdom, the ecological detail outlined above is not included, neither are details regarding point or line features (Fuller et al., 1994b). It is also not currently possible to estimate change from the land cover map series, as the earlier maps use different mapping classes to the later ones (classes that are not directly comparable), and in comparison with CS field data, they have an accuracy of approximately $62 \%$ (in 2007) at the broad habitat level (Morton et al., 2011).

Rather than mapping the full extent of habitats and features within the $1 \mathrm{~km}$ squares, information based on a grid or dispersed points could potentially save time in the field (as, for example, in a 1990s survey of "key habitats"; Hornung et al., 1997; Barr et al., 2017). Whilst this would still provide the potential to produce national estimates for areas, much information regarding point and line features, and landscape structure and pattern would be lost. It is important that any new technologies or methodologies employed must be compatible with the existing databases.

Whilst certain concessions in recording could potentially be made in order to save resource, perhaps particularly for features/habitats with slow rates of change, the current methodology gives an optimal dataset for the full exploration of ecological issues particularly in relation to habitat change, some of which are outlined below.

\section{Use of the data}

The Countryside Survey provides a valuable resource, offering potential for a wide range of analyses at different temporal and spatial scales. A major benefit of the programme is the co-location of a wide range of recorded ecological variables (i.e. soil, vegetation, land cover and water). Monitoring of these variables is of key importance for identifying environ- 
mental change, evaluating policy responses and identifying drivers and processes of ecological change.

The results presented constitute the main findings from CS2007 that have, to date, appeared across a number of UK and country level reports for policy makers (countrysidesurvey.org.uk). CS, in common with comparable national surveys (e.g. Stahl et al., 2011), has been funded for both science and policy objectives (Norton et al., 2012b).

\subsection{Stock and change: national estimates of broad habitat areas}

The recording framework for broad habitats within CS makes it possible to provide national estimates for both the extent (in each survey year) and the change in extent (1990, 1998 and 2007) for broad and priority habitats, using the data from the Countryside Surveys. Estimates of change can be also made using the 1978 and 1984 data, but without the same level of confidence, due to the smaller sample size in those surveys. National estimates of the extent of 17 broad habitats and 12 priority habitats in 1998 and 2007 are presented in Carey et al. (2008). Priority habitats include upland mixed ash wood, wet woodland, upland oakwood, lowland mixed deciduous, upland birch woods, upland and lowland calcareous grassland, upland and lowland dwarf shrub heath, reedbed and purple moor grass rush pasture, as well as the linear feature priority habitat, hedges.

The condition of the vegetation surveyed in each broad habitat has been reported for the 1990, 1998 and 2007 Countryside Surveys. This is because the position of each vegetation plot is known (Wood et al., 2017) and so the species data recorded in each plot can be referenced to a specific broad habitat.

National estimates are based on calculations of the extents of each broad or priority habitat for each of the 45 land classes for England, Scotland and Wales individually, as well as for Great Britain. The procedure traditionally (up until 1998) used for calculating regional or national estimates was to produce means and standard errors for the quantity of interest for each Land Class and then to combine these to produce an estimated mean or total (with associated standard error) for the specified region as described by HainesYoung et al. (2003). The method of combination differed depending on whether a total or mean figure is required, but in both cases it involved weighting the individual land class estimates by values proportional to the area of land within the Land Class. Testing for significance requires more information about the distribution of an estimate than just its standard error. Prior to 1998, significance was assessed by assuming normality of estimates. In 1998, because of concerns about the validity of this assumption, largely because of the skewness of some of the features being estimated, standard errors and confidence intervals for square level data were estimated using the bootstrap method (Efron and Tibshirani, 1993). Essentially bootstrapping involves treating sample data as a population from which to resample. Each resample produces a separate estimate of some quantity of interest, for example stock or change. A large number of resamples (typically 1000 or 10000 ) then gives an approximation to the distribution of the required estimate, from which any statistic can be extracted. The main advantage of this method of estimation for CS is that it allows for non-normality in the data, without requiring details of the actual distribution. As such it provides more accurate measurements of significance.

Prior to 2007, comparison between years was difficult because of the gradual increase in the number of sample squares in each of the years. In CS1998, the change between 1990 and 1998 was calculated using only data from those squares that were surveyed in both 1990 and 1998. Change was only calculated between squares that had been surveyed in both of the years in question, leading to minor discrepancies between the difference between the stock estimates, and the change estimates reported. In order to address this issue of incompatibility and to make better use of all the data collected in the survey, a new analytical procedure, the "consistent model", was developed for CS2007 which uses all available information from the time series (Scott, 2008). National estimates of broad habitats for each survey year for Great Britain are presented in Table 4.

It is important to note that the estimates for 1978 are not directly comparable to those for later surveys published in the Countryside Survey report for 2007 (Carey et al., 2008). This is primarily for two reasons. Firstly, due to the limited sample size of $2561 \mathrm{~km}$ survey squares, estimates have been calculated using the 1990 ITE Land Classification (with 32 classes) rather than the revised 2007 Land Classification (with 45 classes) (see Sect. 2), as there are statistically not enough sample survey squares per class with 45 classes. (For work concentrating specifically on change, it is possible to calculate national estimates for all years using the 1990 Land Classification, but for GB as a whole only.) Secondly, due to the way broad habitats have been allocated retrospectively, habitats may not necessarily equate directly to the later datasets. The national estimates are publicly available, in addition to the raw data (Barr et al., 2014a, b, e, f, i, 1, m; 2015a, b; Brown et al., 2014a, d; Bunce et al., 2012a, b).

\subsection{Stock and change: national estimates of linear and point features}

As with areas, the methods of recording linear and point features have been refined over time, but where there has been consistency of recording over time, the length of linear landscape features and the numbers of point features including trees and ponds (and changes in those lengths and numbers) can be estimated. Assessments of the condition of linear features are confined largely to more recent Countryside Surveys, in particular 1998 and 2007.

Linear features in the countryside are often complex and made up of different components; for example, a single field 
Table 4. Estimated area (thousands of hectares) and percentage of land area of broad habitats in Great Britain from 1978 to 2007 . Note that because of changes in definitions that have been applied retrospectively, the estimates from 1990 and more especially 1984 and 1978 are not in all cases directly comparable with later surveys. (Please note that not all the totals are equal to the sum of the column due to unavailable data.)

\begin{tabular}{|c|c|c|c|c|c|c|c|c|c|c|}
\hline \multirow[b]{3}{*}{ Broad habitat } & \multicolumn{10}{|c|}{ Great Britain } \\
\hline & \multicolumn{2}{|c|}{1978} & \multicolumn{2}{|c|}{1984} & \multicolumn{2}{|c|}{1990} & \multicolumn{2}{|c|}{1998} & \multicolumn{2}{|c|}{2007} \\
\hline & $\begin{array}{r}1000 \mathrm{~s} \\
\text { ha }\end{array}$ & $\begin{array}{c}\% \text { area } \\
\text { of GB }\end{array}$ & $\begin{array}{r}1000 \mathrm{~s} \\
\text { ha }\end{array}$ & $\begin{array}{c}\% \text { area } \\
\text { of GB }\end{array}$ & $\begin{array}{r}1000 \mathrm{~s} \\
\text { ha }\end{array}$ & $\begin{array}{c}\% \text { area } \\
\text { of GB }\end{array}$ & $\begin{array}{r}1000 \mathrm{~s} \\
\text { ha }\end{array}$ & $\begin{array}{c}\% \text { area } \\
\text { of GB }\end{array}$ & $\begin{array}{r}1000 \mathrm{~s} \\
\text { ha }\end{array}$ & $\begin{array}{l}\% \text { area } \\
\text { of GB }\end{array}$ \\
\hline Broadleaved mixed and yew woodland & 995 & 4.3 & 1317 & 5.6 & 1343 & 5.8 & 1328 & 5.7 & 1406 & 6.0 \\
\hline Coniferous woodland & 1413 & 6.1 & 1243 & 5.3 & 1239 & 5.3 & 1386 & 5.9 & 1319 & 5.7 \\
\hline Boundary and linear features & 364 & 1.6 & 491 & 2.1 & 581 & 2.5 & 511 & 2.2 & 496 & 2.1 \\
\hline Arable and horticulture & 5105 & 21.9 & 5283 & 22.7 & 5025 & 21.6 & 5067 & 21.7 & 4608 & 19.8 \\
\hline Improved grassland & 5188 & 22.3 & 5903 & 25.3 & 4619 & 19.8 & 4251 & 18.2 & 4494 & 19.3 \\
\hline Neutral grassland & 1442 & 6.2 & 467 & 2.0 & 1669 & 7.2 & 2007 & 8.6 & 2176 & 9.3 \\
\hline Calcareous grassland & 53 & 0.2 & 75 & 0.3 & 78 & 0.3 & 61 & 0.3 & 57 & 0.2 \\
\hline Acid grassland & 1786 & 7.7 & 1476 & 6.3 & 1821 & 7.8 & 1502 & 6.4 & 1589 & 6.8 \\
\hline Bracken & 258 & 1.1 & 439 & 1.9 & 272 & 1.2 & 315 & 1.3 & 260 & 1.1 \\
\hline Dwarf shrub heath & 1677 & 7.2 & 1388 & 6.0 & 1436 & 6.2 & 1299 & 5.6 & 1343 & 5.8 \\
\hline Fen, marsh, swamp & 231 & 1 & 428 & 1.8 & 427 & 1.8 & 425 & 1.8 & 392 & 1.7 \\
\hline Bog & 2004 & 8.6 & 2303 & 9.9 & 2050 & 8.8 & 2222 & 9.5 & 2232 & 9.6 \\
\hline Standing open waters and canals & 360 & 1.5 & 284 & 1.2 & 200 & 0.9 & 196 & 0.8 & 204 & 0.9 \\
\hline Rivers and streams & 75 & 0.3 & 70 & 0.3 & 70 & 0.3 & 65 & 0.3 & 58 & 0.2 \\
\hline Montane & NA & NA & 41 & 0.2 & NA & NA & 41 & 0.2 & 42 & 0.2 \\
\hline Inland rock & 190 & 0.8 & 38 & 0.2 & 76 & 0.3 & 111 & 0.5 & 101 & 0.4 \\
\hline Built-up areas and gardens & 1441 & 6.2 & 1268 & 5.4 & 1266 & 5.4 & 1279 & 5.5 & 1323 & 5.7 \\
\hline Other land & 249 & 1.1 & NA & NA & 659 & 2.8 & 762 & 3.3 & 731 & 3.1 \\
\hline Unsurveyed urban land & 482 & 2.1 & NA & NA & 482 & 2.1 & 482 & 2.1 & 482 & 2.1 \\
\hline Total area & 23313 & & 23313 & & 23313 & & 23313 & & 23313 & \\
\hline
\end{tabular}

$\mathrm{NA}=$ not available

Table 5. The length (thousands of kilometres) and change in length of boundary and linear features in Great Britain, from 1984 to 2007. Arrows denote significant change $(p<0.05)$ in the direction shown.

\begin{tabular}{lrrrr|rrr}
\hline & & & & & \multicolumn{3}{c}{$\begin{array}{c}\text { Direction of } \\
\text { significant changes }\end{array}$} \\
\hline Hedges & 1984 & 1990 & 1998 & 2007 & $84-90$ & $90-98$ & $98-07$ \\
Line of trees/shrubs/relict hedge & 624 & 506 & 508 & 477 & $\downarrow$ & & $\downarrow$ \\
Line of trees/shrubs/relict hedge/fence & 58 & 71 & 109 & 114 & & $\uparrow$ & $\uparrow$ \\
Walls & 32 & 59 & 99 & 114 & $\uparrow$ & $\uparrow$ & $\uparrow$ \\
Bank/grass strip & 198 & 173 & 176 & 174 & $\downarrow$ & & $\downarrow$ \\
Fence & 56 & 57 & 62 & 64 & & & \\
\hline
\end{tabular}

boundary may contain a fence, a hedge and a bank. To simplify reporting of these features, a hierarchy of feature types was used to define any compound linear feature (Carey et al., 2008) with ecologically important features, hedges and lines of trees at the top of the hierarchy. National estimates for linear feature types (in thousands of kilometres) were achieved by calculating a mean length for each feature type for the sample squares within a land class and then multiplying this figure by the number of $1 \mathrm{~km}$ squares in the land class in a similar method to that described in Sect. 7.1 for areas (Scott et al., 2008). This calculation gives an estimate of the total length in the land class and subsequently, by summation, of all land classes (Table 5). National estimates of ponds and hedgerow tree numbers can be derived in the same way. The national estimates for linear features are publicly available with associated error terms, in addition to the raw data (Barr et al., 2014d, c, h, g, k, j; Brown et al., 2014b, c). 
Table 6. Table of DOIs for landscape element data.

\begin{tabular}{|c|c|c|c|}
\hline & Landscape area data & Landscape linear feature data & Landscape point feature data \\
\hline 1978 & $\begin{array}{l}\text { https://doi.org/10.5285/86c017ba- } \\
\text { dc62-46f0-ad13-c862bf31740e (Bunce } \\
\text { et al., 2016) }\end{array}$ & & \\
\hline 1984 & $\begin{array}{l}\text { https://doi.org/10.5285/b656bb43- } \\
\text { 448d-4b2c-aade-7993aa243ea3 (Barr } \\
\text { et al., 2016g) }\end{array}$ & $\begin{array}{l}\text { https://doi.org/10.5285/a3f5665c- } \\
\text { 94b2-4c46-909e-a98be97857e5 (Barr } \\
\text { et al., 2016f) }\end{array}$ & $\begin{array}{l}\text { https://doi.org/10.5285/124b872e- } \\
\text { 036e-4dd3-8316-476b5f42c16e (Barr } \\
\text { et al., 2016e) }\end{array}$ \\
\hline 1990 & $\begin{array}{l}\text { https://doi.org/10.5285/94f664e5-10f2- } \\
\text { 4655-bfe6-44d745f5dca7 (Barr et al., } \\
\text { 2016h) }\end{array}$ & $\begin{array}{l}\text { https://doi.org/10.5285/311daad4- } \\
\text { bc8c-485a-bc8a-e0d054889219 (Barr } \\
\text { et al., 2016i) }\end{array}$ & $\begin{array}{l}\text { https://doi.org/10.5285/1481bc63- } \\
\text { 80d7-4d18-bcba-8804aa0a9e1b (Barr } \\
\text { et al., 2016a) }\end{array}$ \\
\hline 1998 & $\begin{array}{l}\text { https://doi.org/10.5285/1e050028- } \\
\text { 5c55-42f4-a0ea-c895d827b824 (Barr } \\
\text { et al., 2016b) }\end{array}$ & $\begin{array}{l}\text { https://doi.org/10.5285/8aaf6f8c-c245- } \\
\text { 46bb-8a2a-f0db012b2643 (Barr et al., } \\
\text { 2016d) }\end{array}$ & $\begin{array}{l}\text { https://doi.org/10.5285/ed10944f- } \\
\text { 40c8-4913-b3f5-13c8e844e153 (Barr } \\
\text { et al., 2016c) }\end{array}$ \\
\hline 2007 & $\begin{array}{l}\text { https://doi.org/10.5285/bf189c57- } \\
\text { 61eb-4339-a7b3-d2e81fdde28d } \\
\text { (Brown et al., 2016c) }\end{array}$ & $\begin{array}{l}\text { https://doi.org/10.5285/e1d31245- } \\
\text { 4c0a-4dee-b36c-b23f1a697f88 (Brown } \\
\text { et al., 2016b) }\end{array}$ & $\begin{array}{l}\text { https://doi.org/10.5285/55dc5fd7-d3f7- } \\
\text { 4440-b8a7-7187f8b0550b (Brown et } \\
\text { al., 2016a) }\end{array}$ \\
\hline
\end{tabular}

\section{Wider uses of data to date}

The potential uses of these unique data sets are wide-ranging, and can be broadly divided into two groups: investigations of ecological drivers and process, and provision of evidence to policy makers. CS data give a national overview of changes in habitats (Haines-Young et al., 2003; Firbank et al., 2003; Norton et al., 2012b; Howard et al., 2003). During the production of the National Ecosystem Assessment (NEA) in Britain, CS data (with the inclusion of the Northern Ireland survey) made a vital contribution to our understanding of ecosystems across the UK (NEA UK, 2011). The CS datasets have increasingly been used in the area of ecosystem services and natural capital, for assessing the scale of the benefits that ecosystems provide (Norton et al., 2012a) and investigating the distribution and interdependencies of specific environmental variables (Henrys et al., 2015).

The datasets can also be used to identify and quantify the extent of a particular species. For example, when the Chalara fraxinea ash dieback disease came to prominence in the news in 2012, CS data were used to produce a national picture of ash trees, supplementing information from the Forestry Commission regarding ash in larger woodlands (Forestry Commission, 2012). Estimates of ash as hedgerow trees (Maskell et al., 2013a), within areas less than half a hectare (Maskell et al., 2013b) and individual trees (Maskell et al., 2013c), were drawn from CS data. Data have also been used to assess relationships between wider species richness (birds and plants) and habitat and landscape feature presence and extent (Rhodes et al., 2015; Smart et al., 2010).

Drivers of environmental change may be investigated, for example the effects of agricultural intensification (Petit et al., 2004a) and farming practices (Potter and Lobley, 1996) on habitat quality and extent.

CS data have contributed to the area of woodland research, examining the effects of landscape structure on specific species (Petit et al., 2004a, b; Kimberley et al., 2016). The loss of hedgerows has been a key concern since the end of the Second World War, and CS data have proved useful in determining the extent and nature of changes since 1984 (Barr et al., 1991; Barr and Gillespie, 2000; Petit et al., 2003; Norton et al., 2012b) and applying these to policy changes (Barr and Parr, 1994). CS data have contributed to determining policy, for example the Hedgerow Regulations (The Hedgerows Regulations, 1997). CS linear data have been incorporated into other data products, for example Scholefield et al. (2016a, b).

\section{Data availability}

The datasets have been assigned digital object identifiers as in Table 6.

The most recent (2007) Land Classification is available as Bunce et al. (2007). National estimate datasets are also available as both non-spatial flat files (Barr et al., 2014a, d, e, g, i, k, 1; Brown et al., 2014b, d; Bunce et al., 2012a) and spatial national datasets (Bunce et al., 2012b; Brown et al., 2014c, a; Barr et al., 2014b, c, f, h, j, m, 2015a, b).

The datasets are available from the CEH Environmental Information Data Centre Catalogue (https://catalogue.ceh.ac.uk, last access: 10 April 2018). Datasets are provided under the terms of the Open Government Licence (http://eidchub.ceh.ac.uk/ administration-folder/tools/ceh-standard-licence-texts/ ceh-open-government-licence/plain, last access: 
10 April 2018, http://www.nationalarchives.gov.uk/ doc/open-government-licence/version/3/, last access: 10 April 2018). The metadata are stored in the ISO 19115 (2003) schema (International Organization for Standardization, 2015) in the UK Gemini 2.1 profile (UK GEMINI, 2015). Users of the datasets will find the following documents useful (supplied as supporting documentation with the datasets): Bunce (1978), Maskell et al. (2008), Barr and Wood (2011), and Barr (1984, 1990, 1998).

\section{Conclusions}

The ecological landscape element data recorded during the Countryside Survey of Great Britain are an invaluable national resource, which, over the years, has proved useful to a range of users, including the scientific community and national policy makers. The data are collected in a statistically robust and quality-controlled manner, follow standard, repeatable methods and cover wide temporal and spatial scales. The intention is that a repeat survey will be undertaken in the near future (and a sub-sample of plots have already been surveyed in the summer of 2016, mainly in Wales, largely as part of the Glastir Monitoring and Evaluation Programme; Emmett and GMEP team, 2014). As a decade has now passed since the most recent full survey, an addition to this long-term national resource is becoming increasingly timely, particularly in these current times of political, socioeconomic and climatic change. The latest news regarding further surveys can be found on the website for the programme, www.countrysidesurvey.org.uk (last access: 10 April 2018).

Author contributions. CMW prepared the manuscript with significant contributions from all co-authors, and is the current database manager for the Land Use Research Group at CEH Lancaster. RGHB designed the sampling framework and survey strategy in 1978. RGHB, SMS, LCM, LRN and DCH have all been part of the Countryside Survey scientific co-ordination team for at least one survey, with WAS and PAH contributing statistical support, and SMW, MJB, RJS, RS and JWW providing technical and data management support.

Competing interests. The authors declare that they have no conflict of interest.

Acknowledgements. We thank all the landowners who kindly gave permission to survey their holdings in the survey sample squares in 1978, 1984, 1990, 1998 and 2007. Without their cooperation and assistance the Countryside Survey would not exist. We also acknowledge and thank all the field surveyors involved in each field campaign.

The most recent Countryside Survey was funded largely by the Natural Environment Research Council, the Department for Envi- ronment Food and Rural Affairs, and the Scottish and Welsh governments.

We would like to thank an anonymous reviewer and Geoffrey Griffiths for valuable comments which improved the manuscript.

Edited by: David Carlson

Reviewed by: Geoffrey Griffiths and one anonymous referee

\section{References}

Bakkestuen, V., Erikstad, L., and Halvorsen, R.: Step-less models for regional environmental variation in Norway, J. Biogeogr., 35, 1906-1922, 2008.

Barr, C.: Countryside Survey 1984 field handbook, Institute of Terrestrial Ecology, Grange-over-Sands, 1984.

Barr, C.: Countryside Survey 1990 field handbook, Institute of Terrestrial Ecology, Grange-over-Sands, 1990.

Barr, C. and Gillespie, M.: Estimating hedgerow length and pattern characteristics in Great Britain using Countryside Survey data, J. Environ. Manage., 60, 23-32, https://doi.org/10.1006/jema.2000.0359, 2000.

Barr, C., Howard, D., Bunce, B., Gillespie, M., and Hallam, C.: Changes in hedgerows in Britain between 1984 and 1990. Contract report to the Department Of The Environment, Institute of Terrestrial Ecology, Grange-over-Sands, 1991.

Barr, C. J.: Countryside Survey 2000 Field Handbook, Institute of Terrestrial Ecology, Grange-over-Sands, 1998.

Barr, C. J. and Parr, T. W.: Hedgerows: Linking Ecological Research and Countryside Policy, in: Hedgerow Management and Nature Conservation, edited by: Watt, T. A. and Buckley, G. P., Wye College Press, University of London, 1994.

Barr, C. J. and Wood, C. M.: The Sampling Strategy for Countryside Survey (up to 2007). Revised and Updated from: "The Sampling Strategy for Countryside Survey", C. J. Barr, September 1998. DETR CONTRACT No. CR0212, Lancaster, 2011.

Barr, C. J., Brown, M. J., Bunce, R. G. H., Carey, P. D., Chandler, K., Clarke, R. T., Crowe, A., Gillespie, M. K., Hallam, C. J., Howard, D. C., Maskell, L. C., Ness, M. J., Norton, L. R., Scott, R. J., Scott, W. A., Smart, S. M., Stuart, R. C., Watkins, J. W., Wood, C. M., and Wright, S. M.: Countryside Survey estimates of Broad Habitat area change in Great Britain between 1990, 1998 and 2007, NERC Environmental Information Data Centre, Lancaster, UK, https://doi.org/10.5285/7e2981e7-bd4c-4992-b7b01b1253bfd20d, 2014a.

Barr, C. J., Brown, M. J., Bunce, R. G. H., Carey, P. D., Chandler, K., Clarke, R. T., Crowe, A., Gillespie, M. K., Hallam, C. J., Howard, D. C., Maskell, L. C., Ness, M. J., Norton, L. R., Scott, R. J., Scott, W. A., Smart, S. M., Stuart, R. C., Wood, C. M., and Wright, S. M.: Countryside Survey mapped estimates of Broad Habitat area change in Great Britain between 1990 and 2007, NERC Environmental Information Data Centre, https://doi.org/10.5285/4af5abe4-158a-4736b318-ec660e09e45a, 2014b.

Barr, C. J., Bunce, R. G. H., Clarke, R. T., Gillespie, M. K., Hallam, C. J., Howard, D. C., Maskell, L. C., Ness, M. J., Norton, L. R., Scott, R. J., Scott, W. A., Smart, S. M., Stuart, R. C., Wood, C. M., and Wright, S. M.: Countryside Survey 1990 mapped estimates of linear feature 
lengths in Great Britain, NERC Environmental Information Data Centre, https://doi.org/10.5285/ce514508-bd25-403ebb35-42001e3c2b25, 2014c.

Barr, C. J., Bunce, R. G. H., Clarke, R. T., Gillespie, M. K., Hallam, C. J., Howard, D. C., Maskell, L. C., Ness, M. J., Norton, L. R., Scott, R. J., Scott, W. A., Smart, S. M., Stuart, R. C., Wood, C. M., and Wright, S. M.: Countryside Survey 1990 estimates of linear feature lengths in Great Britain, NERC Environmental Information Data Centre, https://doi.org/10.5285/ebbd1ba0-4497-4c80-891a34ef3b8989cd, 2014d.

Barr, C. J., Bunce, R. G. H., Clarke, R. T., Gillespie, M. K., Hallam, C. J., Howard, D. C., Maskell, L. C., Ness, M. J., Norton, L. R., Scott, R. J., Scott, W. A., Smart, S. M., Stuart, R. C., Wood, C. M., and Wright, S. M.: Countryside Survey 1990 estimates of Broad Habitat areas in Great Britain, NERC Environmental Information Data Centre, https://doi.org/10.5285/32dda22c-24cc-4fa8-adcb5481b1b77ef1, 2014e.

Barr, C. J., Bunce, R. G. H., Clarke, R. T., Gillespie, M. K., Hallam, C. J., Howard, D. C., Maskell, L. C., Ness, M. J., Norton, L. R., Scott, R. J., Scott, W. A., Smart, S. M., Stuart, R. C., Wood, C. M., and Wright, S. M.: Countryside Survey 1990 mapped estimates of Broad Habitat areas in Great Britain, NERC Environmental Information Data Centre, https://doi.org/10.5285/53ef00f4-e0c5-4095-850ed4c474bc4ffd, 2014f.

Barr, C. J., Bunce, R. G. H., Clarke, R. T., Gillespie, M. K., Howard, D. C., Maskell, L. C., Norton, L. R., Scott, R. J., Scott, W. A., Smart, S. M., Stuart, R. C., Watkins, J. W., Wood, C. M., and Wright, S. M.: Countryside Survey 1998 estimates of linear feature lengths in Great Britain, NERC Environmental Information Data Centre, $\quad$ https://doi.org/10.5285/59422890-c8d3-49b8-b17e4f5062475140, 2014g.

Barr, C. J., Bunce, R. G. H., Clarke, R. T., Gillespie, M. K., Howard, D. C., Maskell, L. C., Norton, L. R., Scott, R. J., Scott, W. A., Smart, S. M., Stuart, R. C., Watkins, J. W., Wood, C. M., and Wright, S. M.: Countryside Survey 1998 mapped estimates of linear feature lengths in Great Britain, NERC Environmental Information Data Centre, https://doi.org/10.5285/6bc0ccb4-63c8-4121-bc4b3c479877cff9, 2014h.

Barr, C. J., Bunce, R. G. H., Clarke, R. T., Gillespie, M. K., Howard, D. C., Maskell, L. C., Norton, L. R., Scott, R. J., Scott, W. A., Smart, S. M., Stuart, R. C., Watkins, J. W., Wood, C. M., and Wright, S. M.: Countryside Survey 1998 estimates of Broad Habitat areas in Great Britain, NERC Environmental Information Data Centre, https://doi.org/10.5285/acbb0f9c-f2a5-4cbd-97c384e786f2e479, $2014 \mathrm{i}$.

Barr, C. J., Bunce, R. G. H., Maskell, L. C., Norton, L. R., Scott, R. J., Scott, W. A., Smart, S. M., Stuart, R. C., Whittaker, H. A., Wood, C. M., and Wright, S. M.: Countryside Survey 1984 mapped estimates of linear feature lengths in Great Britain, NERC Environmental Information Data Centre, https://doi.org/10.5285/362bff26-d2ca-4700-b1f022072f4bc0cc, 2014j.
Barr, C. J., Bunce, R. G. H., Maskell, L. C., Norton, L. R., Scott, R. J., Scott, W. A., Smart, S. M., Stuart, R. C., Whittaker, H. A., Wood, C. M., and Wright, S. M.: Countryside Survey 1984 estimates of linear feature lengths in Great Britain, NERC Environmental Information Data Centre, https://doi.org/10.5285/271d398c-29de-4ff9-ba681b8e0621c6ee, 2014k.

Barr, C. J., Bunce, R. G. H., Maskell, L. C., Norton, L. R., Scott, R. J., Scott, W. A., Smart, S. M., Stuart, R. C., Whittaker, H. A., Wood, C. M., and Wright, S. M.: Countryside Survey 1984 estimates of Broad Habitat areas in Great Britain, NERC Environmental Information Data Centre, https://doi.org/10.5285/ad823866-cded-4778-9bd7999c821b120e, 20141.

Barr, C. J., Bunce, R. G. H., Maskell, L. C., Norton, L. R., Scott, R. J., Scott, W. A., Smart, S. M., Stuart, R. C., Whittaker, H. A., Wood, C. M., and Wright, S. M.: Countryside Survey 1984 mapped estimates of Broad Habitat areas in Great Britain, NERC Environmental Information Data Centre, https://doi.org/10.5285/5964c7a2-0537-40d79d1b-76c37c3aadf2, 2014m.

Barr, C. J., Brown, M. J., Bunce, R. G. H., Carey, P. D., Chandler, K., Crowe, A., Gillespie, M. K., Howard, D. C., Maskell, L. C., Norton, L. R., Scott, R. J., Scott, W. A., Smart, S. M., Stuart, R. C., Watkins, J. W., Wood, C. M., and Wright, S. M.: Countryside Survey mapped estimates of Broad Habitat area change in Great Britain between 1998 and 2007, NERC Environmental Information Data Centre, https://doi.org/10.5285/d83a0f9e-00c9-4d2d-9d0ae92a16dcb334, 2015a.

Barr, C. J., Bunce, R. G. H., Clarke, R. T., Gillespie, M. K., Hallam, C. J., Howard, D. C., Maskell, L. C., Ness, M. J., Norton, L. R., Scott, R. J., Scott, W. A., Smart, S. M., Stuart, R. C., Watkins, J. W., Wood, C. M., and Wright, S. M.: Countryside Survey mapped estimates of Broad Habitat area change in Great Britain between 1990 and 1998, NERC Environmental Information Data Centre, https://doi.org/10.5285/2bfdede9-8008-4ba3ac8e-af4e6ab9888b, 2015b.

Barr, C. J., Bunce, R. G. H., Clarke, R. T., Gillespie, M. K., Hallam, C. J., Howard, D. C., Maskell, L. C., Ness, M. J., Norton, L. R., Scott, R. J., Scott, W. A., Smart, S. M., Stuart, R. C., Wood, C. M., and Wright, S. M.: Landscape point feature data 1990 [Countryside Survey], NERC Environmental Information Data Centre, https://doi.org/10.5285/1481bc63-80d74d18-bcba-8804aa0a9e1b, 2016a.

Barr, C. J., Bunce, R. G. H., Clarke, R. T., Gillespie, M. K., Howard, D. C., Maskell, L. C., Norton, L. R., Scott, R. J., Scott, W. A., Smart, S. M., Stuart, R. C., Watkins, J. W., Wood, C. M., and Wright, S. M.: Landscape area data 1998 [Countryside Survey], NERC Environmental Information Data Centre, https://doi.org/10.5285/1e050028-5c55-42f4-a0eac895d827b824, 2016b.

Barr, C. J., Bunce, R. G. H., Clarke, R. T., Gillespie, M. K., Howard, D. C., Maskell, L. C., Norton, L. R., Scott, R. J., Scott, W. A., Smart, S. M., Stuart, R. C., Watkins, J. W., Wood, C. M., and Wright, S. M.: Landscape point feature data 1998 [Countryside Survey], NERC Environmental Information Data Centre, https://doi.org/10.5285/ed10944f-40c8-4913-b3f513c8e844e153, 2016c. 
Barr, C. J., Bunce, R. G. H., Clarke, R. T., Gillespie, M. K., Howard, D. C., Maskell, L. C., Norton, L. R., Scott, R. J., Scott, W. A., Smart, S. M., Stuart, R. C., Watkins, J. W., Wood, C. M., and Wright, S. M.: Landscape linear feature data 1998 [Countryside Survey], NERC Environmental Information Data Centre, https://doi.org/10.5285/8aaf6f8c-c245-46bb-8a2af0db012b2643, 2016d.

Barr, C. J., Bunce, R. G. H., Maskell, L. C., Norton, L. R., Scott, R. J., Scott, W. A., Smart, S. M., Stuart, R. C., Whittaker, H. A., Wood, C. M., and Wright, S. M.: Landscape point feature data 1984 [Countryside Survey], NERC Environmental Information Data Centre, https://doi.org/10.5285/124b872e036e-4dd3-8316-476b5f42c16e, 2016e.

Barr, C. J., Bunce, R. G. H., Maskell, L. C., Norton, L. R., Scott, R. J., Scott, W. A., Smart, S. M., Stuart, R. C., Whittaker, H. A., Wood, C. M., and Wright, S. M.: Landscape linear feature data 1984 [Countryside Survey], NERC Environmental Information Data Centre, https://doi.org/10.5285/a3f5665c94b2-4c46-909e-a98be97857e5, $2016 f$.

Barr, C. J., Bunce, R. G. H., Maskell, L. C., Norton, L. R., Scott, R. J., Scott, W. A., Smart, S. M., Stuart, R. C., Whittaker, H. A., Wood, C. M., and Wright, S. M.: Landscape area data 1984 [Countryside Survey], NERC Environmental Information Data Centre, https://doi.org/10.5285/b656bb43-448d-4b2caade-7993aa243ea3, 2016g.

Barr, C. J., Bunce, R. G. H., Clarke, R. T., Gillespie, M. K., Hallam, C. J., Howard, D. C., Maskell, L. C., Ness, M. J., Norton, L. R., Scott, R. J., Scott, W. A., Smart, S. M., Stuart, R. C., Wood, C. M., and Wright, S. M.: Landscape area data 1990 [Countryside Survey], https://doi.org/10.5285/94f664e5-10f2-4655-bfe644d745f5dca7, 2016h.

Barr, C. J., Bunce, R. G. H., Clarke, R. T., Gillespie, M. K., Hallam, C. J., Howard, D. C., Maskell, L. C., Ness, M. J., Norton, L. R., Scott, R. J., Scott, W. A., Smart, S. M., Stuart, R. C., Wood, C. M., and Wright, S. M.: Landscape linear feature data 1990 [Countryside Survey], $2016 \mathrm{i}$.

Barr, C. J., Bunce, R. G. H., Cummins, R. P., Hallam, C. J., Hornung, M., and Wood, C. M.: Habitat and vegetation data from an ecological survey of terrestrial key habitats in England, 1992-1993, NERC Environmental Information Data Centre, https://doi.org/10.5285/7aefe6aa-0760-4b6d-9473fad8b960abd4, 2017.

Bartholomé, E. and Belward, A.: GLC2000: a new approach to global land cover mapping from Earth observation data, Int. J. Remote Sens., 26, 1959-1977, https://doi.org/10.1080/01431160412331291297, 2005.

Brandt, J., Bunce, R., Howard, D., and Petit, S.: General principles of monitoring land cover change based on two case studies in Britain and Denmark, Landscape Urban Plan., 62, 37-51, 2002.

Brown, M. J., Bunce, R. G. H., Carey, P. D., Chandler, K., Crowe, A., Maskell, L. C., Norton, L. R., Scott, R. J., Scott, W. A., Smart, S. M., Stuart, R. C., Wood, C. M., and Wright, S. M.: Countryside Survey 2007 mapped estimates of Broad Habitat areas in Great Britain, NERC Environmental Information Data Centre, https://doi.org/10.5285/bb785c19-3cf64483-9fe5-13829d489a83, 2014a.

Brown, M. J., Bunce, R. G. H., Carey, P. D., Chandler, K., Crowe, A., Maskell, L. C., Norton, L. R., Scott, R. J., Scott, W. A., Smart, S. M., Stuart, R. C., Wood, C. M., and
Wright, S. M.: Countryside Survey 2007 estimates of linear feature lengths in Great Britain, NERC Environmental Information Data Centre, https://doi.org/10.5285/e687330b-a0f7-45a1-b58c398e67da3028, 2014b.

Brown, M. J., Bunce, R. G. H., Carey, P. D., Chandler, K., Crowe, A., Maskell, L. C., Norton, L. R., Scott, R. J., Scott, W. A., Smart, S. M., Stuart, R. C., Wood, C. M., and Wright, S. M.: Countryside Survey 2007 mapped estimates of linear feature lengths in Great Britain, NERC Environmental Information Data Centre, https://doi.org/10.5285/fc65177d-b113420e-a70b-05d3f42682d5, 2014c.

Brown, M. J., Bunce, R. G. H., Carey, P. D., Chandler, K., Crowe, A., Maskell, L. C., Norton, L. R., Scott, R. J., Scott, W. A., Smart, S. M., Stuart, R. C., Wood, C. M., and Wright, S. M.: Countryside Survey 2007 estimates of Broad Habitat areas in Great Britain, NERC Environmental Information Data Centre, https://doi.org/10.5285/f03cba75-8bca-4679-ae2a77a9fcbd4df3, 2014d.

Brown, M. J., Bunce, R. G. H., Carey, P. D., Chamberlain, P. M., Chandler, K., Crowe, A., Maskell, L. C., Norton, L. R., Scott, R. J., Scott, W. A., Smart, S. M., Stuart, R. C., Wood, C. M., and Wright, S. M.: Landscape point feature data 2007 [Countryside Survey], NERC Environmental Information Data Centre, https://doi.org/10.5285/55dc5fd7-d3f7-4440-b8a77187f8b0550b, 2016a.

Brown, M. J., Bunce, R. G. H., Carey, P. D., Chandler, K., Crowe, A., Maskell, L. C., Norton, L. R., Scott, R. J., Scott, W. A., Smart, S. M., Stuart, R. C., Wood, C. M., and Wright, S. M.: Landscape linear feature data 2007 [Countryside Survey], NERC Environmental Information Data Centre, https://doi.org/10.5285/e1d31245-4c0a-4dee-b36cb23f1a697f88, 2016b.

Brown, M. J., Bunce, R. G. H., Carey, P. D., Chandler, K., Crowe, A., Maskell, L. C., Norton, L. R., Scott, R. J., Scott, W. A., Smart, S. M., Stuart, R. C., Wood, C. M., and Wright, S. M.: Landscape area data 2007 [Countryside Survey], NERC Environmental Information Data Centre, https://doi.org/10.5285/bf189c57-61eb-4339-a7b3d2e81fdde28d, 2016c.

Bunce, R. G. H.: UK Ecological Survey. Handbook of Field Methods, Institute of Terrestrial Ecology, Grange-over-Sands, 1978.

Bunce, R. G. H. and Smith, R. S.: An ecological survey of Cumbria, Structure Plan Working Paper, 4, Cumbria County Council and Lake District Special Planning Board, Kendal, 1978.

Bunce, R. G. H., Barr, C. J., Clarke, R. T., Howard, D. C., and Lane, A. M. J.: ITE Land Classification of Great Britain 1990, NERC Environmental Information Data Centre, https://doi.org/10.5285/ab320e08-faf5-48e1-9ec977a213d2907f, 1990.

Bunce, R. G. H., Barr, C. J., Clarke, R. T., Howard, D. C., and Lane, A. M. J.: ITE Merlewood Land Classification of Great Britain, J. Biogeogr., 23, 625-634, https://doi.org/10.1111/j.1365-2699.1996.tb00023.x, 1996a.

Bunce, R. G. H., Barr, C. J., Clarke, R. T., Howard, D. C., and Lane, A. M. J.: Land classification for strategic ecological survey, J. Environ. Manage., 47, 37-60, https://doi.org/10.1006/jema.1996.0034, 1996b.

Bunce, R. G. H., Barr, C. J., Gillespie, M. K., and Howard, D. C.: The ITE Land Classification: providing an environmental strat- 
ification of Great Britain, Environ. Monit. Assess., 39, 39-46, https://doi.org/10.1007/978-94-009-1653-1_5, 1996c.

Bunce, R. G. H., Barr, C. J., Clarke, R. T., Howard, D., and Scott, A.: ITE Land Classification of Great Britain 2007, NERC Environmental Information Data Centre, https://doi.org/10.5285/5f0605e4-aa2a-48ab-b47cbf5510823e8f, 2007.

Bunce, R. G. H., Wood, C. M., Henrys, P. A., Smart, S. M., Howard, D. C., and Barr, C. J.: Countryside Survey 1978 estimates of Broad Habitat areas in Great Britain, NERC Environmental Information Data Centre, $\quad$ https://doi.org/10.5285/c8feabac-7c3f-4c35-91f7296782b957d1, 2012a.

Bunce, R. G. H., Wood, C. M., Henrys, P. A., Smart, S. M., Howard, D. C., and Barr, C. J.: Countryside Survey 1978 mapped estimates of Broad Habitat areas in Great Britain, NERC Environmental Information Data Centre, $\quad$ https://doi.org/10.5285/df180b2e-36ea-410e-84875a09942afa9e, 2012b.

Bunce, R. G. H., Bogers, M. M. B., Evans, D., and Jongman, R. H. G.: Field identification of habitats directive Annex I habitats as a major European biodiversity indicator, Ecological Indicators, 33, 105-110, https://doi.org/10.1016/j.ecolind.2012.10.004, 2013.

Bunce, R. G. H., Wood, C. M., Henrys, P. A., Smart, S. M., Howard, D. C., and Barr, C. J.: Landscape area data 1978 [Countryside Survey], NERC Environmental Information Data Centre, https://doi.org/10.5285/86c017ba-dc62-46f0-ad13c862bf31740e, 2016.

Carey, P. D., Wallis, S., Chamberlain, P. M., Cooper, A., Emmett, B. A., Maskell, L. C., McCann, T., Murphy, J., Norton, L. R., Reynolds, B., Scott, W. A., Simpson, I. C., Smart, S. M., and Ullyett, J. M.: Countryside Survey: UK Results from 2007, NERC/Centre for Ecology \& Hydrology, Lancaster, 2008.

Cole, B., King, S., Ogutu, B., Palmer, D., Smith, G., and Balzter, H.: Corine land cover 2012 for the UK, Jersey and Guernsey, NERC Environmental Information Data Centre, https://doi.org/10.5285/32533dd6-7c1b-43e1-b892e80d61a5ea1d, 2015.

Cooper, A.: Land cover monitoring in Northern Ireland, Biodiversity: the Irish dimension, edited by: Rushton, B. S., Royal Irish Academy, Dublin, 122-131, 2000

Cooper, A., McCann, T., and Rogers, D.: Northern Ireland countryside survey 2007: Broad Habitat change 1998-2007, Northern Ireland Environment Agency, Coleraine, 2009.

Dunbar, M., Murphy, J., Clarke, R., Baker, R., Davies, C., and Scarlett, P.: Countryside Survey: headwater streams report from 2007, CS Technical Report No. 8/07, NERC Centre for Ecology and Hydrology, Wallingford, 2010.

Efron, B. and Tibshirani, R. J.: An introduction to the bootstrap, Chapman and Hall, London, 1993

Elena-Rosselló, R.: Biogeoclimatic classification of the Spanish regions of Iberian Peninsula and Balearic islands, Ministry of Agriculture, Fisheries and Food, Madrid, 2007.

Emmett, B. E. and GMEP team: Glastir Monitoring \& Evaluation Programme, First Year Annual Report to Welsh Government (Contract reference: C147/2010/11), NERC/Centre for Ecology \& Hydrology, Bangor, 442 pp., 2014.
Emmett, B. A., Reynolds, B., Chamberlain, P. M., Rowe, E., Spurgeon, D., Brittain, S. A., Frogbrook, Z., Hughes, S., Lawlor, A. J., Poskitt, J., Potter, E., Robinson, D. A., Scott, A., Wood, C., and Woods, C.: Countryside Survey: Soils Report from 2007, Centre for Ecology \& Hydrology, Wallingford, UK, 2010.

Esri: http://www.esri.com/, last access: 23 August 2017.

Eva, H. D., Belward, A. S., De Miranda, E. E., Di Bella, C. M., Gond, V., Huber, O., Jones, S., Sgrenzaroli, M., and Fritz, S.: A land cover map of South America, Glob. Change Biol., 10, 731-744, https://doi.org/10.1111/j.1529-8817.2003.00774.x, 2004.

Firbank, L. G., Barr, C. J., Bunce, R. G. H., Furse, M. T., Haines-Young, R. H., Hornung, M., Howard, D. C., Sheail, J., Sier, A. R. J., and Smart, S. M.: Assessing stock and change in land cover and biodiversity in GB: an introduction to the Countryside Survey 2000, J. Environ. Manage., 67, 207-218, https://doi.org/10.1016/S0301-4797(02)00174-3, 2003.

Forestry Commission: NFI preliminary estimates of quantities of broadleaved species in British woodlands, with special focus on ash, Forestry Commission, available at: https://www.forestry.gov.uk/pdf/NFI_Prelim_BL_Ash_ Estimates.pdf/\$FILE/NFI_Prelim_BL_Ash_Estimates.pdf (last access: 10 April 2018), Edinburgh, 2012.

Fuller, R. M., Groom, G. B., and Jones, A. R.: The land cover map of Great Britain: an automated classification of Landsat Thematic Mapper data, Photogramm. Eng. Rem. S., 60, 553-562, 1994a.

Fuller, R. M., Sheail, J., and Barr, C. J.: The Land of Britain, 1930-1990: a comparative study of Field Mapping and Remote Sensing Techniques, Geogr. J., 160, 173-184, https://doi.org/10.2307/3060075, 1994b.

Fuller, R. M., Smith, G. M., Sanderson, J. M., Hill, R. A., Thomson, A. G., Cox, R., Brown, N. J., Clarke, R. T., Rothery, P., and Gerard, F. F.: Land Cover Map 2000 - Module 7 final report, NERC Centre for Ecology \& Hydrology, Huntingdon, 2001.

Haines-Young, R., Barr, C., Firbank, L., Furse, M., Howard, D., McGowan, G., Petit, S., Smart, S., and Watkins, J.: Changing landscapes, habitats and vegetation diversity across Great Britain, J. Environ. Manage., 67, 267-281, https://doi.org/10.1016/S03014797(02)00179-2, 2003.

Henrys, P., Bee, E., Watkins, J., Smith, N., and Griffiths, R.: Mapping natural capital: optimising the use of national scale datasets, Ecography, 38, 632-638, https://doi.org/10.1111/ecog.00402, 2015.

Hornung, M. F., Barr, C. J., and Bunce, R. G. H.: Current status and prospects for key habitats in England. Part 6: Summary report, Institute of Terrestrial Ecology, Grange-over-Sands, 1997.

Howard, D., Watkins, J., Clarke, R., Barnett, C., and Stark, G.: Estimating the extent and change in Broad Habitats in Great Britain, J. Environ. Manage., 67, 219-227, https://doi.org/10.1016/S0301-4797(02)00175-5, 2003.

International Organization for Standardization: ISO 19115:2003: http://www.iso.org/iso/catalogue_detail.htm?csnumber=26020, last access: 12 October 2015.

Jackson, D.: Guidance on the Interpretation of the Biodiversity Broad Habitat Classification (Terrestrial and Freshwater Types): Definitions and the Relationship with Other Habitat Classifications (JNCC Report, No 307), JNCC, published online, available at: http://jncc.defra.gov.uk/page-2433 (last access: 10 April 2018), 73 pp., 2000. 
Kimberley, A., Blackburn, G. A., Whyatt, J. D., and Smart, S. M.: How well is current plant trait composition predicted by modern and historical forest spatial configuration?, Ecography, 39, 6776, https://doi.org/10.1111/ecog.01607, 2016.

Maddock, A.: UK Biodiversity Action Plan; Priority Habitat Descriptions, published online, available at: http://jncc.defra.gov. uk/PDF/UKBAP_PriorityHabitatDesc-Rev2011.pdf (last access: 10 April 2018), 2008.

Maskell, L. C., Norton, L. R., Smart, S. M., Carey, P. D., Murphy, J., Chamberlain, P. M., Wood, C. M., Bunce, R. G. H., and Barr, C. J.: Countryside Survey. Field Mapping Handbook CS Technical Report No. 1/07, Centre for Ecology \& Hydrology, Lancaster, 2008.

Maskell, L. C., Henrys, P. A., Norton, L. R., Smart, S. M., and Wood, C. M.: Distribution of Ash trees (Fraxinus excelsior) in Countryside Survey data, NERC Centre for Ecology \& Hydrology, Lancaster, 2013a.

Maskell, L. C., Henrys, P. A., Norton, L. R., Smart, S. M., and Wood, C. M.: Distribution of ash trees within areas less than half a hectare in Great Britain, NERC Environmental Information Data Centre, https://doi.org/10.5285/7f7c99c7-5457-444d978a-fe7b01a85fd0, 2013b.

Maskell, L. C., Henrys, P. A., Norton, L. R., Smart, S. M., and Wood, C. M.: Distribution of individual ash trees in Great Britain, NERC Environmental Information Data Centre, https://doi.org/10.5285/0c3567a8-3700-4d52-a21fde1bd709141a, 2013c.

Mayaux, P., Bartholomé, E., Fritz, S., and Belward, A.: A new landcover map of Africa for the year 2000, J. Biogeogr., 31, 861-877, 2004.

Metzger, M. J., Brus, D. J., Bunce, R. G. H., Carey, P. D., Gonçalves, J., Honrado, J. P., Jongman, R. H. G., Trabucco, A., and Zomer, R.: Environmental stratifications as the basis for national, European and global ecological monitoring, Ecol. Indic., 33, 26-35, https://doi.org/10.1016/j.ecolind.2012.11.009, 2013.

Morton, D., Rowland, C., Wood, C., Meek, L., Marston, C., Smith, G., Wadsworth, R., and Simpson, I.: Final Report for LCM2007 - the new UK land cover map, CS Technical Report No. 9/07, NERC/Centre for Ecology \& Hydrology, Wallingford, 2011.

NEA UK: The UK national ecosystem assessment, UNEP-WCMC, Cambridge, 2011.

Norton, L. R., Scholefield, P. S., Maskell, L. C., Smart, S. M., Murphy, J., Williams, P., Scarlett, P., and Clarke, R.: Quality Assurance Report: MAPPING QUALITY ASSURANCE EXERCISE Centre for Ecology and Hydrology, Lancaster, 2008.

Norton, L., Inwood, H., Crowe, A., and Baker, A.: Trialling a method to quantify the "cultural services" of the English landscape using Countryside Survey data, Land Use Policy, 29, 449455, https://doi.org/10.1016/j.landusepol.2011.09.002, 2012a.

Norton, L. R., Maskell, L. C., Smart, S. M., Dunbar, M. J., Emmett, B. A., Carey, P. D., Williams, P., Crowe, A., Chandler, K., Scott, W. A., and Wood, C. M.: Measuring stock and change in the GB countryside for policy: key findings and developments from the Countryside Survey 2007 field survey, J. Environ. Manage., 113, 117-127, https://doi.org/10.1016/j.jenvman.2012.07.030, 2012b.

Oracle: https://www.oracle.com, last access: 23 August 2017.
Petit, S., Stuart, R., Gillespie, M., and Barr, C.: Field boundaries in Great Britain: stock and change between 1984, 1990 and 1998, J. Environ. Manage., 67, 229-238, https://doi.org/10.1016/S03014797(02)00176-7, 2003.

Petit, S., Griffiths, L., Smart, S. S., Smith, G. M., Stuart, R. C., and Wright, S. M.: Effects of area and isolation of woodland patches on herbaceous plant species richness across Great Britain, Landsc. Ecol., 19, 463-471, https://doi.org/10.1023/B:LAND.0000036141.30359.53, 2004a.

Petit, S., Howard, D. C., and Stuart, R. C.: A national perspective on recent changes in the spatial characteristics of woodland in the British landscape, Landscape Urban Plan., 69, 127-135, https://doi.org/10.1016/j.landurbplan.2003.10.031, 2004b.

Potter, C. and Lobley, M.: The farm family life cycle, succession paths and environmental change in Britain's countryside, J. Agr. Econ., 47, 172-190, https://doi.org/10.1111/j.14779552.1996.tb00683.x, 1996.

Prosser, M. V. and Wallace, H. L.: Countryside Survey 1990 Quality Assurance Exercise, Report to Institute of Terrestrial Ecology, Merlewood Research Station, Canon Pyon, Herefordshire, 1992.

Prosser, M. V. and Wallace, H. L.: Countryside Survey 2000 Quality Assurance Exercise, Report to Institute of Terrestrial Ecology, Merlewood Research Station, Second draft, Canon Pyon, Herefordshire, 1999.

Rhodes, C. J., Henrys, P., Siriwardena, G. M., Whittingham, M. J., and Norton, L. R.: The relative value of field survey and remote sensing for biodiversity assessment, Methods Ecol. Evol., 6, 772-781, https://doi.org/10.1111/2041-210X.12385, 2015.

Romão, C.: Interpretation manual of European Union habitats, version EUR 28, available at: http://ec.europa.eu/environment/ nature/legislation/habitatsdirective/docs/Int_Manual_EU28.pdf (last access: 10 April 2018), 2013.

Scholefield, P., Morton, D., Rowland, C., Henrys, P., Howard, D., and Norton, L.: A model of the extent and distribution of woody linear features in rural Great Britain, Ecol. Evol., 6, 8893-8902, https://doi.org/10.1002/ece3.2607, 2016a.

Scholefield, P. A., Morton, R. D., Rowland, C. S., Henrys, P. A., Howard, D. C., and Norton, L. R.: Woody linear features framework, Great Britain v.1.0, NERC Environmental Information Data Centre, https://doi.org/10.5285/d7da6cb9-104b-4dbcb709-c1f7ba94fb16, 2016b.

Scott, W. A.: Countryside Survey. Statistical Report, Countryside Survey Technical Report No. 4/07, NERC Centre for Ecology and Hydrology, Lancaster, 2008.

Sheail, J. and Bunce, R. G. H.: The development and scientific principles of an environmental classification for strategic ecological survey in the United Kingdom, Environ. Conserv., 30, 147-159, https://doi.org/10.1017/S0376892903000134, 2003.

Smart, S., Maskell, L., Dunbar, M., Emmett, B., Marks, S., Norton, L., Rose, P., and Simpson, I.: An Integrated Assessment of Countryside Survey data to investigate Ecosystem Services in Great Britain. Countryside Survey Technical Report No. 10/07, NERC Centre for Ecology and Hydrology, Lancaster, 2010.

Ståhl, G., Allard, A., Esseen, P.-A., Glimskär, A., Ringvall, A., Svensson, J., Sundquist, S., Christensen, P., Torell, Å. G., and Högström, M.: National Inventory of Landscapes in Sweden (NILS) - scope, design, and experiences from establishing a multiscale biodiversity monitoring system, Environ. Monit. As- 
sess., 173, 579-595, https://doi.org/10.1007/s10661-010-1406-7, 2011.

The Hedgerows Regulations: The Hedgerows Regulations 1997, available at: http://www.legislation.gov.uk/uksi/1997/1160/ contents/made (last access 10 April 2018), 1997.

UK GEMINI: UK GEMINI, http://www.agi.org.uk/join-us/ agi-groups/standards-committee/uk-gemini, last access: 12 May 2015.

Villoslada, M., Bunce, R. G. H., Sepp, K., Jongman, R. H. G., Metzger, M. J., Kull, T., Raet, J., Kuusemets, V., Kull, A., and Leito, A.: A framework for habitat monitoring and climate change modelling: construction and validation of the Environmental Stratification of Estonia, Reg. Environ. Change, 17, 1-15, https://doi.org/10.1007/s10113-016-1002-7, 2016.

Williams, P., Biggs, J., Crowe, A., Murphy, J., Nicolet, P., Weatherby, A., and Dunbar, M.: Countryside survey: ponds report from 2007. CS Technical Report No. 7/07. Pond Conservation and NERC/Centre for Ecology \& Hydrology, Wallingford, 2010.

Wood, C. M. and Bunce, R. G. H.: Survey of the terrestrial habitats and vegetation of Shetland, 1974 - a framework for longterm ecological monitoring, Earth Syst. Sci. Data, 8, 89-103, https://doi.org/10.5194/essd-8-89-2016, 2016.
Wood, C. M., Howard, D. C., Henrys, P. A., Bunce, R. G. H., and Smart, S. M.: Countryside Survey: measuring habitat change over 30 years: 1978 data rescue - final report, NERC Centre for Ecology \& Hydrology, Lancaster, 2012.

Wood, C. M., Norton, L. R., and Rowland, C. S.: What are the costs and benefits of using aerial photography to survey habitats in $1 \mathrm{~km}$ squares?, NERC Centre for Ecology \& Hydrology, Lancaster, UK, 2015.

Wood, C. M., Smart, S. M., Bunce, R. G. H., Norton, L. R., Maskell, L. C., Howard, D. C., Scott, W. A., and Henrys, P. A.: Longterm vegetation monitoring in Great Britain - the Countryside Survey 1978-2007 and beyond, Earth Syst. Sci. Data, 9, 445459, https://doi.org/10.5194/essd-9-445-2017, 2017.

Wyatt, B., Greatorex-Davies, J., Hill, M., Parr, T., Bunce, R., and Fuller, R.: Comparisons of land cover definitions, Department of Environment Countryside 1990 Series, Vol. 3, HMSO, London, 1994. 